\title{
ANÁLISIS COMPARATIVO DE LOS SISTEMAS DE APLICACIÓN PRIVADA Y PÚBLICA DE LAS NORMAS DE LIBRE COMPETENCIA EN LOS PAÍSES INTEGRANTES DE LA COMUNIDAD ANDINA*
}

\author{
COMPARATIVE ANALYSIS OF THE \\ PRIVATE AND PUBLIC APPLICATION \\ SYSTEMS FOR THE FREE MARKET \\ COMPETITION LAWS IN THE MEMBER \\ STATES OF THE ANDEAN COMMUNITY
}

\author{
Ingrid S. Ortiz-Baquero** \\ Diego A. Solano-Osorio*** \\ Fecha de recepción: 24 de mayo de 2016 \\ Fecha de aceptación: 30 de junio de 2016 \\ Disponible en línea: 30 de noviembre de 2016
}

\section{Para citar este artículo/To cite this article}

\begin{abstract}
Ortiz-Baquero, Ingrid S. \& Solano-Osorio, Diego A., Análisis comparativo de los sistemas de aplicación privada y pública de las normas de libre competencia en los países integrantes de la Comunidad Andina, 133 Vniversitas, 191-226 (2016). http://dx.doi.org/10.11144/Javeriana.vj133.acsa
\end{abstract}

doi: 10.11144/Javeriana.vj133.acsa

* Este artículo hace parte del proyecto de investigación La aplicación privada o judicial de las normas de libre competencia en la Comunidad Andina de Naciones y sus países integrantes, llevado a cabo en el Grupo de Investigación de Derecho Comercial de la Universidad Externado de Colombia.

** Abogada, especialista en Derecho comercial y magíster en responsabilidad contractual y extracontractual civil y del Estado, Universidad Externado de Colombia. Diploma de estudios avanzados en derecho mercantil y doctora en derecho mercantil, Universidad Autónoma de Madrid, UAM. Magíster en derecho y economía del consumo, Universidad de Castilla-La Mancha, UCLM. Docente investigadora, Universidad Externado de Colombia. Contacto: ingrido.ortiz@uexternado.edu.co

*** Abogado y especialista en derecho comercial, Universidad Externado de Colombia. Asistente de investigación y asistente en la cátedra de comercial quinto año, Títulos Valores, Universidad Externado de Colombia. Contacto: diego.solano@uexternado.edu.co 


\section{RESUMEN}

El modelo de aplicación privada de las normas del derecho de la competencia se ha impuesto recientemente en el derecho continental como un mecanismo adicional e idóneo al tradicional sistema público, que ha logrado reforzar el cabal cumplimiento de las normas protectoras de la competencia. Sin embargo, la introducción de este sistema en el derecho europeo se ha dado tras un largo y consolidado desarrollo del public enforcement, que ve las acciones de daños como su complemento, más allá de considerarlo como su detractor. En este sentido, el presente documento pretende analizar las características de cada uno de los modelos de aplicación y llegar a unas conclusiones que permitan consolidar un sistema eficiente contra las conductas anticompetitivas.

Palabras clave: aplicación privada; aplicación pública; Comunidad Andina; acción de daños; acciones de nulidad; derecho de la competencia 


\section{ABSTRACT}

The private application model for the application of the regulations of the competition law recently became in continental law as an additional and more suitable mechanism than the traditional public system, having achieved reinforced the full compliance of the laws protecting competence. However, the introduction of this system in European law happened after a long and established development of public enforcement, which sees damage claims as its complement, instead of seeing it as its detractor. To this effect, this document aims to analyze the characteristics of each one of the application models in order to reach conclusions that allow for the consolidation of an efficient system against anticompetitive behaviors.

Keywords: private application; public application; Andean Community; damage claims; invalidity claims; competition rights

\section{SUMARIO}

INTRODUCCIÓN.- I. ARguMENTOS EN DEFENSA DEL SISTEMA DE ENFORCEMENT PÚBLICO EN LA CAN.- A. El modelo público facilita la armonización entre los ordenamientos nacionales.- B. La adecuada defensa del interés general requiere el fortalecimiento del modelo público.- C. La consolidación del modelo público como antecedente del sistema private enforcement: el efecto directo de las normas andinas.- II. AvANCES HACIA UN SISTEMA DE APLiCACión JUdicial EN los PAíses INTEgRANTES DE la CAN.- $A$. Cambios bajo el nuevo modelo de aplicación de las normas de libre competencia.- B. Los efectos jurídico-privados de las infracciones de competencia.- CONCLUSIONES.- BIBLIOGRAFÍA. 


\section{INTRODUCCIÓN}

Una vez esbozadas las principales características que identifican el modelo público de aplicación de las normas del derecho de la competencia en los países que forman parte de la Comunidad Andina, CAN, en esta segunda parte de la investigación, corresponde realizar un análisis comparativo de las ventajas y desventajas de uno y otro modelo de aplicación, tal como lo habíamos anunciado.

Nuestra finalidad es, en primera medida, destacar la prevalencia del modelo público de aplicación de las normas de libre competencia tanto en el mercado andino como en cada mercado nacional, identificar los beneficios que hasta el momento ha arrojado este modelo así como sus problemas y vacíos, tomando el modelo comunitario europeo como punto de referencia para esta valoración, comparación y crítica; todo ello para finalmente evaluar la pertinencia y la utilidad que tendría implementar un sistema de private enforcement en estos ámbitos.

Es preciso advertir que el desarrollo del tema y las conclusiones que arroja su estudio son distintos según el nivel en el que se realice su análisis. Tal como se expondrá a lo largo de este trabajo, en el contexto andino - dados el nivel actual de integración y de desarrollo de las normas comunitarias de protección de la competencia-, la opción más acertada parece ser la de promover el fortalecimiento del modelo público de aplicación de las normas de libre competencia. Por el contrario, en el contexto de los estados integrantes de la CAN, la aprobación de normas nuevas sobre competencia, la actualización de otras más antiguas, y en general las experiencias recientes en la materia, son indicios claros sobre los grandes avances hacia la implementación del sistema de aplicación judicial o private enforcement, que antes que excluir o eliminar el sistema público pretende complementarlo y fortalecerlo.

\section{ARGUMENTOS EN DEFENSA DEL SISTEMA DE ENFORCEMENT PÚBLICO EN LA CAN}

A pesar de nuestra opinión favorable al aprovechamiento de las experiencias foráneas, somos escépticos en recomendar dentro del 
contexto andino la implementación inmediata y sin filtros de un modelo de private enforcement como el establecido en Europa a partir del Reglamento (CE) $1 / 2003^{12}$.

Consideramos que en la actual fase de desarrollo del derecho andino de la competencia y de la CAN como ente supranacional, lo más conveniente es fortalecer en el ámbito comunitario el modelo enforcement público. En particular, se deberían reforzar las acciones de las autoridades tanto nacionales como comunitarias de competencia y los procedimientos de este orden. Asimismo, se deberían adoptar medidas para incrementar las sanciones económicas, garantizar su cumplimiento y extender su aplicación a las personas naturales.

Creemos que solo una vez consolidado el modelo público (primordialmente en lo referente a la interpretación y valoración de las conductas anticompetitivas y el sistema de excepciones) y fortalecidas las instituciones nacionales de competencia (administrativa y financieramente), puede plantearse el salto hacia un sistema de carácter judicial. En este punto es importante recordar que, en el ámbito europeo el paso a un sistema de private enforcement solo tuvo lugar después de más de 40 años de desarrollo del modelo público, momento para el cual tanto en el ámbito comunitario como en el nacional ya se tenían las bases necesarias para permitir la intervención de los jueces nacionales y de los particulares por medio de las acciones de daños y de nulidad en este ámbito.

Nuestra opinión no debe ser interpretada en el sentido de que se deban obstaculizar los avances que respecto al private enforcement se podrían abrir paso en los ordenamientos nacionales y que a futuro podrían constituir la base del desarrollo de un sistema de privado

1 Consejo de la Unión Europea, Reglamento (CE) 1/2003 del Consejo, de 16 de diciembre de 2002 , relativo a la aplicación de las normas sobre competencia previstas en los artículos 81 y 82 del Tratado, L1 Diario Oficial de las Comunidades Europeas, 4 de enero de 2003. Disponible en: http://eur-lex.europa.eu/LexUriServ/LexUriServ.do?uri=OJ:L:2003:001:0001:0025:ES:PDF

2 De la misma opinión parece ser FrancISCO MARCos, que en referencia a la política de defensa de la competencia en Ecuador señala: "En principio cabe pensar que el sistema de aplicación del derecho de defensa de la competencia en Ecuador puede complementarse con una previsión de las posibles acciones judiciales de los perjudicados para reclamar a los infractores los daños y perjuicios provocados por la realización de prácticas prohibidas, pero la introducción de este tipo de acciones o de un sistema de aplicación privada del derecho de defensa de la competencia debe ir precedida de una reflexión previa sobre sus objetivos y su adecuación a la realidad e instituciones ecuatorianas”. FrancISCO MARCOS, ¿Una politica de competencia para la República de Ecuador?, 21 Boletín Latinoamericano de Competencia, 2, 29-39, 37 (febrero de 2006). Disponible en: http://ec.europa.eu/competition/publications/blc/boletin_21_2.pdf 
en el contexto comunitario ${ }^{3}$; nuestro criterio únicamente significa que deben valorarse los beneficios que se han logrado por medio del sistema público y los que podrían obtenerse con su fortalecimiento, sin negar ni desconocer la importancia de los avances conscientes y sopesados hacia el modelo de aplicación judicial.

\section{A. El modelo público facilita la armonización entre los ordenamientos nacionales}

No obstante los avances y los puntos en común entre los ordenamientos nacionales, no hay aún un desarrollo uniforme y armónico del derecho de la libre competencia en los Estados que conforman la $\mathrm{CAN}^{4}$.

En efecto, mientras Perú y Colombia tienen desde hace más de dos décadas normas y autoridades de competencia y, por consiguiente, un bagaje y una experiencia ganada como resultado de la aplicación de sus leyes y la gestión de sus instituciones; en Bolivia y Ecuador el tema ha venido adquiriendo importancia lentamente, pero por ahora, carece de trayectoria y enfrenta los retos políticos que este tipo de normativa suscita.

Bolivia reguló por primera vez de forma general el tema de la libre competencia por medio del Decreto Supremo 29519/20085. Sus tradiciones, sus experiencias y sus logros en este campo por ahora están limitadas a los ámbitos sectoriales cubiertos por la Ley SIRE-

3 Como un punto favorable a la implementación de un sistema de aplicación judicial, encontramos el reconocimiento que el Tribunal Andino de Justicia hace de los principios de supremacía, prevalencia, autonomía y efecto directo del derecho comunitario, que valga recordar fueron los principios que permitieron en Europa el reconocimiento de las competencias de los jueces nacionales para aplicar el ordenamiento de la libre competencia y proteger los intereses y derechos privados que conferían estas normas. Así pues, la consolidación de los órganos comunitarios, la expansión del ámbito de sus actuaciones y la profundización del proceso de integración harán que a futuro los principios y características que se reconocen al derecho andino trasciendan a la práctica y permitan la interacción de los jueces nacionales en cuanto a la aplicación de la legislación antitrust comunitaria.

4 Se precisa en todo caso, que tanto Ecuador como Bolivia cuentan con normas sectoriales (electricidad, telecomunicaciones, mercado de valores, sector financiero, seguros, etc.) que incluyen o incorporan disposiciones en materia de libre competencia. Una relación de esta normativa y de su fuente de consulta puede consultarse en: JUAN DAVID GUTIÉRREZ-RODRÍGUEZ, La legislación de competencia en América Latina y el Caribe: historia, vigencia, aplicación y reformas (Centro de Estudios de Derecho de la Competencia, Working paper 07-05, 2007). Disponible en: http://papers.ssrn.com/sol3/papers.cfm?abstract_id=1023811

5 Bolivia, Decreto Supremo 29519, que regula la competencia y la defensa del consumidor frente a conductas lesivas, 16 de abril de 2008. Disponible en: http://www.autoridadempresas.gob. bo/marco-legal/decretos-supremos 
$\mathrm{SE}^{6}$. Infortunadamente, los avances que se preveía alcanzar con las nuevas disposiciones se han visto truncados por la eliminación de la Superintendencia de Empresas, que era la autoridad encargada de promover y proteger la libre competencia y de aplicar el Decreto Supremo 29519/2008 y las normas andinas. Aunque teóricamente estas competencias han sido asumidas por el Ministerio de Desarrollo Productivo y Economía Plural, no hay en la actualidad directrices sobre este punto, ni tampoco claridad sobre la orientación que seguirá el gobierno boliviano en torno a la protección de la libre competencia. Tampoco hay información sobre la forma en que ese Ministerio está aplicando o piensa aplicar la normativa nacional y andina y, por consiguiente, hay un total desconcierto entre los distintos actores económicos sobre el futuro regulatorio.

Después de numerosos intentos por disponer de una normativa general de libre competencia, Ecuador logró la expedición de la Ley Orgánica de Regulación y Control del Poder de Mercado, discutida y aprobada en tan solo un mes por parte de la Asamblea Nacional, y promulgada por el presidente constitucional de la República, el 11 de octubre de $2011^{7}$.

El desarrollo de los temas de libre competencia en Perú y en Colombia se ha visto acelerado por las negociaciones adelantadas por cada uno de estos países con Estados Unidos con ocasión de la firma de los Tratados de Libre Comercio ${ }^{8}$. Estos acuerdos han impuesto a los legisladores nacionales la obligación de garantizar el funcionamiento de un modelo de aplicación de las normas de competencia que además de ser efectivo asegure el adecuado fun-

6 En el ordenamiento boliviano se ha confiado la protección de la libre competencia en los sectores cobijados por la Ley SIRESE (Sistema de Regulación Sectorial) a las denominadas Superintendencias Sectoriales; junto a ellas, la Superintendencia de Empresas también tenía competencias en la materia. Bolivia, Decreto Supremo 24505, Reglamento a la Ley del Sistema de Regulación Sectorial, SIRESE, 21 de febrero de 1997. Disponible en: http://www.lexivox. org/norms/BO-DS-24505.xhtml

7 Ecuador, Ley Orgánica de Regulación y Control del Poder del Mercado, Registro Oficial, Suplemento 555, 13 de octubre de 2011. Disponible en: http://www.planificacion.gob.ec/wpcontent/uploads/downloads/2012/10/Ley-Organica.pdf

8 Perú \& Estados Unidos, Acuerdo de Promoción Comercial Perú-Estados Unidos, TLC, Washington D.C., 12 de abril de 2006, vigente desde el 1 de febrero de 2009. Disponible en: http://www.acuerdoscomerciales.gob.pe/index.php?option=com_content\&view=category\&lay out=blog\&id=55\&Itemid=78. Colombia \& Estados Unidos, Acuerdo de Promoción Comercial entre la República de Colombia y Estados Unidos de América, TLC, Washington D.C., 22 de noviembre de 2006, vigente desde el 15 de mayo de 2012. Disponible en: http://www.tlc.gov. co/publicaciones.php?id=14853 
cionamiento del mercado tanto para las empresas nacionales como para los inversores y empresas extranjeras.

Ante este panorama de desigualdad, para superar las diferencias aún existentes en la región y, por ende, para poder conseguir una armonización en la materia (en los aspectos sustanciales y procesales) y en vía de fortalecimiento de la integración subregional, se impone la defensa del modelo público de aplicación de las normas de libre competencia, como camino a seguir?

A nuestro juicio, en este modelo de aplicación resulta más fácil orientar las acciones de las autoridades nacionales de competencia y es más sencillo controlar sus resultados ${ }^{10}$. Igualmente, se impone como la vía idónea para promover las labores de coordinación y de cooperación entre las autoridades administrativas y el desarrollo de los procesos de intercambio de experiencias con miras a fortalecer las instituciones nacionales y por esta vía, lograr un apoyo más fuerte y constante a los órganos comunitarios ${ }^{11}$.

A nuestro juicio, este proceso de armonización mediante el modelo público conllevaría el desarrollo de varias etapas:

La primera etapa debería incluir grosso modo los siguientes pasos: el primero y principal ya se ha logrado toda vez que la totalidad de los países andinos disponen de normas generales de libre competencia y de autoridades que garantizan su aplicación. Un segundo paso es el de implementar medidas, programas y seminarios, tanto en Ecuador como en Bolivia, para incentivar el conocimiento y la familiarización de las empresas y los consumidores con el contenido de las normas de libre competencia ${ }^{12}$. Un tercer

9 Creemos que el proceso de integración regional es la vía adecuada para garantizar que la inserción de los países en las economías mundiales no se convierta en fuente de pobreza. Al respecto, Bernardo Vela, La encrucijada del proceso andino de integración, 12 Oasis, 425432, 426-427 (2007). Disponible en: http://revistas.uexternado.edu.co/index.php/oasis/article/ view/2432/2070

10 También es un factor importante a tener en cuenta las facultades de abogacía de la competencia que ejercen estas entidades frente a otras de carácter público, las cuales les permiten una mayor comunicación interinstitucional, mayor efectividad en sus actuaciones y mayor control de los sectores económicos que deben ser vigilados de forma más intensa.

11 Este proceso de fortalecimiento y de capacitación de las autoridades nacionales de competencia se ha venido promoviendo y apoyando desde la Organización para la Cooperación y el Desarrollo Económicos, OCDE y el Banco Internacional de Reconstrucción y Fomento, BIRF.

12 Sobre la situación existente en el ordenamiento jurídico boliviano, LORENA OTERo afirma: “(...) Las superintendencias están realizando esfuerzos para poner en conocimiento de la sociedad los objetivos del sistema de regulación y su utilidad social, informando sobre sus actividades y la de los sectores regulados. A pesar de estos esfuerzos queda mucho por hacer para consolidar 
paso consiste en establecer y/o fortalecer la función de "abogacía de la competencia" a cargo de las autoridades nacionales para evitar la promulgación de normas que afecten la libre competencia o la gestión de entidades públicas que pueda tener este efecto. En cuarto lugar, será necesario implementar un sistema de intercambio de experiencias y de revisión de los procedimientos que adelantan las autoridades nacionales para identificar fortalezas y vacíos. Y, finalmente, un quinto paso consistiría en el diseño de mecanismos de cooperación entre las autoridades nacionales para garantizar una aplicación más efectiva de las normas andinas.

En una segunda etapa, sería necesario a efectos de fortalecer el desarrollo de las normas comunitarias de competencia, conceder a las autoridades nacionales la facultad de aplicar estas disposiciones. En esta línea sería importante clarificar el funcionamiento del sistema de exención de conductas en el ámbito comunitario. Hasta el momento, la Decisión 608/2005 $5^{13}$ únicamente contempla la aplicación de exenciones a solicitud de los Estados miembros y referidas a sectores económicos en su integridad; por lo tanto, sería conveniente dejar abierta la posibilidad a la concesión de exenciones de carácter singular tanto comunitarias como nacionales ${ }^{14}$. Desde

el sistema regulatorio. Por ejemplo, en algún proceso de demanda de actos anticompetitivos, las autoridades regulatorias deben basarse en doctrina y legislación extranjera al momento de determinar sobre la procedencia o improcedencia de la demanda". LoRENA OTERo, El derecho de la competencia en Bolivia, 2 Revista Centro de Estudios Derecho de la Competencia, 2, 15-31, 25 (2006). Disponible en: https://centrocedec.files.wordpress.com/2010/06/1-el-dercho-de-l.pdf. Destaca el artículo 38 de la Ley Orgánica de Regulación y Control del Poder de Mercado que en su numeral 17 confiere a la Superintendencia de Control del Poder de Mercado la facultad de "(...) suscribir convenios con asociaciones de usuarios y consumidores para la promoción de la participación de la comunidad en el fomento de la competencia y transparencia de los mercados".

13 Comisión de la Comunidad Andina, CAN, Decisión 608/2005, Normas para la protección y promoción de la libre competencia en la Comunidad Andina, Lima, Perú, 28 de marzo de 2005. Disponible en: http://intranet.comunidadandina.org/Documentos/decisiones/DEC608. doc

14 En el ordenamiento, Colombia solo contempla la concesión de autorizaciones sectoriales (parágrafo del artículo 1 de la Ley 155 de 1959 y artículo 5 de la Ley 1340 de 2009). Colombia, Ley 155 de 1959, por la cual se dictan algunas disposiciones sobre prácticas comerciales restrictivas, 30.138 Diario Oficial, 22 de enero de 1960. Disponible en: http://www.alcaldiabogota. gov.co/sisjur/normas/Normal.jsp?i=38169. Colombia, Ley 1340 de 2009, por medio de la cual se dictan normas en materia de protección de la competencia, 47.420 Diario Oficial, 24 de julio de 2009. Disponible en: http://www.secretariasenado.gov.co/senado/basedoc/ley_1340_2009. $\mathrm{html}$. Perú únicamente regula las conductas que están exentas por ley (art. 3 del DL 1034 de 2008). Perú, Decreto Legislativo 1034, que aprueba la Ley de Represión de Conductas Anticompetitivas, Diario Oficial El Peruano, 25 de junio de 2008. Disponible en: https://www. indecopi.gob.pe/documents/51771/196578/d11034.pdf/66c0472e-46de-4eb3-b872-7369c5279583. Bolivia prevé dentro del análisis y la valoración de las conductas anticompetitivas de carác- 
luego, las exenciones —en el ámbito comunitario-únicamente podrían ser concedidas por la Secretaría General.

Somos de la opinión de que un sistema como el que funcionó en Europa hasta antes del Reglamento (CE) 1/2003, permite a los órganos comunitarios y a las autoridades nacionales adquirir la experiencia necesaria en la aplicación de las prohibiciones, en la delimitación de su extensión y en la necesidad de una interpretación y aplicación racionalizada de ellas. Igualmente, este sistema contribuye a la introducción de criterios de interpretación económica $\mathrm{y}$, en general, al mejor conocimiento de los mercados nacionales y de la CAN. En este sentido, un sistema de carácter público permite promover el desarrollo y el fortalecimiento de un mercado único que es - como lo fue en Europa - uno de los objetivos y pilares de la integración económica andina.

Tras la implementación de todas estas medidas, en una tercera etapa, podrían adoptarse otras supranacionales con el fin de fortalecer los poderes de las autoridades comunitarias y de coordinar sus funciones con la que desarrollan las autoridades nacionales de competencia, $\mathrm{ANC}^{15}$.

Así las cosas, el fin último de este proceso de armonización sería el de lograr una aplicación administrativa descentralizada de las normas andinas de competencia y la creación de las bases para un sistema de cooperación entre autoridades administrativas semejante a la Red Europea de Autoridades de Competencia.

ter relativo (artículo 10 del Decreto Supremo 29519 de 2008), la valoración de las ventajas y eficiencias a favor - fundamentalmente - de los consumidores; sin embargo, este análisis según lo prevé la norma debe hacerse dentro del proceso de determinación de la ilicitud de la conducta y no como criterio de exención de la misma. Bolivia, Decreto Supremo 29519, que regula la competencia y la defensa del consumidor frente a conductas lesivas, 16 de abril de 2008. Disponible en: http://www.autoridadempresas.gob.bo/marco-legal/decretos-supremos. Ecuador dentro de su normativa de competencia introduce importantes avances en este punto, destaca en particular el reconocimiento de la aplicación de la regla de minimis. Ecuador, Ley Orgánica de Regulación y Control del Poder del Mercado, Registro Oficial, Suplemento 555, 13 de octubre de 2011. Disponible en: http://www.planificacion.gob.ec/wp-content/uploads/ downloads/2012/10/Ley-Organica.pdf

15 En el éxito de este proceso, la expedición de directrices o pautas generales que orienten las actividades de las empresas y las funciones de las autoridades nacionales de competencia juega un papel importante. Estas disposiciones además permitirían paliar el desbalance que genera la desigualdad de tradiciones y experiencias y, al tiempo, aprovechar la trayectoria de las autoridades con mayores conocimientos en la materia. Así, en efecto, en la elaboración de las directrices generales podrían tener un papel importante las autoridades de competencia de Perú y Colombia, y las superintendencias sectoriales de Bolivia; en otros términos, se trataría de marcar derroteros con base en las experiencias que ya existen en la región, para lograr una armonización más rápida. 


\section{B. La adecuada defensa del interés general requiere el fortalecimiento del modelo público}

En defensa del fortalecimiento del sistema público nacional y andino, hay que señalar que este modelo es el que mejor protege los intereses de la colectividad.

En economías como las de los países andinos (todos en vía de desarrollo) y en pleno apogeo de los acuerdos de libre comercio con otros grupos subregionales o con países desarrollados, la defensa de la competencia se convierte en una garantía para las empresas y los inversores extranjeros $\mathrm{y}$, a su vez, en un mecanismo para la protección de los derechos e intereses de los empresarios y de los consumidores locales.

En este escenario, el Estado es el que tiene el deber de garantizar que la competencia se desarrolle en condiciones de igualdad y libertad, y el que tiene la carga de adoptar todas las medidas para evitar que las ventajas de los acuerdos de libre comercio se diluyan a consecuencia de los comportamientos restrictivos, o peor aún, expongan a las empresas nacionales a las prácticas anticompetitivas de las extranjeras ${ }^{16}$.

La preponderancia de la acción de las entidades administrativas es particularmente importante en mercados pequeños, cerrados y de economías emergentes, en los que suele ser frecuente la existencia de carteles y de conductas abusivas ${ }^{17}$. En estas circunstancias es poco probable que los particulares promuevan acciones privadas,

16 Muestra de la importancia del sistema público de defensa y aplicación de las normas de competencia, es que incluso en aquellos países donde se acepta la aplicación judicial, el modelo público conserva su vigencia. Las decisiones judiciales no pueden impedir ni limitar las facultades y poderes de las autoridades administrativas para imponer sanciones y adoptar medidas orientadas hacia la protección del orden público económico; adicionalmente, aunque reconocemos que los jueces pueden amparar el orden público, su función principal no es la de atender este objetivo sino la reclamación de un derecho del que es titular un particular dentro de un conflicto de esta categoría.

17 Sobre el carácter preponderante de los carteles en las economías de Perú y Colombia, pueden verse los peer review presentados por cada uno de estos países a la OCDE y que están disponibles en la web de esta entidad: http://www.oecd.org/document/36/0,3343, en_40382599_40393122_40424036_1_1_1_1,00.html. Adicionalmente, DANIEL CRANE sostiene que el private enforcement puede complementar la labor que realizan las ANC y contribuir a la lucha contra los carteles en Latinoamérica. Daniel CRANE, Private Enforcement against International Cartels in Latin America: A US Perspective, en Competition Law and Policy in Latin America, 326-350, 327 (Eleanor M. Fox \& D. Daniel Sokol, eds., Hart Publishing, Oxford, 2009). Si bien reconocemos la veracidad de este presupuesto, consideramos que aún no es el momento de dar cabida a un modelo para el que no hay bases ni antecedentes necesarios. 
tanto por desconocimiento de las normas que les sirven de fundamento, como por los costos que tendrían que asumir para probar la conducta ilícita, con lo cual la acción más eficaz - y casi siempre la única- es la que corresponde a las entidades públicas que además disponen a su favor de los medios necesarios para intervenir, investigar, sancionar e implementar el desarrollo de los programas de clemencia orientados a aumentar la detección de los carteles ${ }^{18} \mathrm{y}$, en general, la sanción de las conductas anticompetitivas ${ }^{19}$.

Adicionalmente, la acción de las autoridades nacionales de competencia favorece los poderes de policía administrativa que les permiten adelantar actuaciones de oficio, intervenir en aquellos sectores que sean más conflictivos y de mayor relevancia y, por supuesto, recaudar la información necesaria para establecer la infracción.

18 Sobre la problemática que puede surgir entre la aplicación de los programas de clemencia y un modelo de aplicación privada de las normas de derecho de la competencia: "En este sentido, uno de los inconvenientes principales que se ponen de manifiesto en relación al uso en la práctica de los programas de clemencia es que la colaboración por parte de las empresas infractoras con las autoridades públicas, confesando la existencia de un cártel o bien aportando pruebas con un 'valor añadido significativo', tiene efectos en relación al expediente sancionador administrativo, que puede derivar en una exención total o reducción del importe que la empresa ha de pagar en concepto de multa sancionadora, pero no con respecto a la responsabilidad civil por daños y perjuicios que se puede derivar frente a los perjudicados singularmente considerados, además del acceso de estos últimos a los documentos que la empresa infractora hubiese aportado a la autoridad de defensa de la competencia en el marco de los programas de clemencia”. Patricia Pérez-Fernández, La problemática relación entre los programas de clemencia y las acciones privadas de resarcimiento de los daños derivados de ilícitos antitrust, 1 InDret, Revista para el Análisis del Derecho, 1-23 (2013). Disponible en: http://www.raco.cat/ index.php/InDret/article/download/262214/349397

19 Colombia estableció la aplicación de un sistema de clemencia en el artículo 14 de la Ley 1340 de 2009, reglamentado por el Decreto 1523 de 2015. Colombia, Decreto 1523 de 2015, por medio del cual se reglamenta el artículo 14 de la Ley 1340 de 2009 y se modifica el Capítulo 29 del Título 2 de la Parte 2 del Libro 2 del Decreto Único Reglamentario del Sector Comercio, Industria y Turismo, Decreto 1074 de 2015, sobre beneficios a las personas naturales y jurídicas que colaboren en la detección y represión de acuerdos restrictivos de la libre competencia, 49.575 Diario Oficial, 16 de julio de 2015. Disponible en: http://www.alcaldiabogota.gov.co/ sisjur/normas/Norma1.jsp?i=62539. Perú regula este sistema en el artículo 26 del Decreto Ley 1034 de 2008, Bolivia lo hace en el artículo 13 del Decreto Supremo 29519 de 2008 y Ecuador en los artículos 83 y 84 de la Ley de Regulación y Control del Poder de Mercado. Perú, Decreto Legislativo 1034, que aprueba la Ley de Represión de Conductas Anticompetitivas, Diario Oficial El Peruano, 25 de junio de 2008. Disponible en: https://www.indecopi.gob.pe/ documents/51771/196578/d11034.pdf/66c0472e-46de-4eb3-b872-7369c5279583. Bolivia, Decreto Supremo 29519, que regula la competencia y la defensa del consumidor frente a conductas lesivas, 16 de abril de 2008. Disponible en: http://www.autoridadempresas.gob.bo/marco-legal/ decretos-supremos. Ecuador, Ley Orgánica de Regulación y Control del Poder del Mercado, Registro Oficial, Suplemento 555, 13 de octubre de 2011. Disponible en: http://www.planificacion. gob.ec/wp-content/uploads/downloads/2012/10/Ley-Organica.pdf 
Así las cosas, a nuestro juicio, fortalecer el modelo público en esta fase de integración significa garantizar una mayor efectividad de las normas de competencia en la región y una protección de los intereses generales. Para cumplir este propósito será esencial dotar a las entidades de los recursos económicos necesarios para su adecuado funcionamiento, adoptar medidas para garantizar su independencia política, fortalecer los programas de delación, incrementar las multas y plantear el debate sobre la pertinencia de sanciones penales en este ámbito respecto de las conductas especialmente restrictivas (hard core cartels) ${ }^{20}$.

Desde otra perspectiva, es preciso tener en cuenta que la defensa del modelo público en el ámbito de los países andinos está reforzada por el inadecuado funcionamiento de la administración de justicia. Al colapso de la función judicial que a su vez genera graves atrasos en la resolución de conflictos, se suman los costos que tendrían que asumir los particulares que deciden actuar ante estas instancias y la carencia de los medios probatorios a la que se verían expuesta con el fin de comprobar la existencia de una conducta ilícita. En conclusión, la concesión de competencias a los jueces para aplicar de forma directa las normas de competencia puede ser catastrófica si no se adoptan medidas previas que hagan que los procesos sean más cortos, menos costosos y sobre todo más efectivos. En nuestro ámbito, los beneficios anteriores podrían lograrse con la efectiva creación de los jueces de lo mercantil en la medida en que estos tendrían una competencia especializada y podrían dar un trámite más rápido y efectivo a las reclamaciones de las empresas.

20 En Perú, el artículo 10.II del Decreto Supremo 29519 de 2008 establece que los agentes que incurran en conductas anticompetitivas además de las sanciones administrativas serán sujetos pasivos de la responsabilidad civil o penal y el artículo 12.II señala que la aplicación de las reducciones propias del sistema de delación (clemencia) no excluye las restantes acciones que pudieren corresponder a consecuencia de las conductas anticompetitivas. Por su parte, el artículo 38 del proyecto de Ley de Defensa de la Competencia de Ecuador prevé que en caso de encontrarse indicios de responsabilidad penal el expediente debe remitirse al Ministerio Público para que este inicie los trámites pertinentes. 


\section{La consolidación del modelo público como antecedente del sistema private enforcement: el efecto directo de las normas andinas}

En el contexto andino, al igual que en el europeo, el Tribunal de Justicia de la Comunidad Andina (en adelante, TJCA) ha reconocido que las normas comunitarias tienen efecto directo, vinculante y preeminente para los Estados miembros y para todos sus ciudada$\operatorname{nos}^{21}$. Estas características de la normativa andina se complementan con el deber de cooperación que se establece a cargo de los Estados miembros y como consecuencia del cual se reconoce que los jueces nacionales son jueces comunitarios del derecho común.

Aunque estas características parecerían en principio ser suficientes - tal como lo fueron en Europa - para aceptar e incluso promover el reconocimiento del efecto directo de las normas de competencia y, por consiguiente, el deber de los jueces nacionales de proteger los derechos que ellas confieren, lo cierto - a nuestro juicio- es que los principios y reglas que orientan la aplicación del derecho comunitario no son una razón suficiente ni absoluta para defender la estructuración - inmediata - de un nuevo modelo de aplicación judicial de la normativa antitrust en el contexto comunitario.

21 "Mientras que el principio de la aplicación directa se refiere a la norma como tal, el efecto directo se relaciona con las acciones que los sujetos beneficiarios pueden ejercer para la debida aplicación de la norma comunitaria. En otras palabras que sus efectos 'generan derechos y obligaciones para los particulares al igual que ocurre en las normas de los ordenamientos estatales', permitiendo la posibilidad de que aquellos puedan exigir directamente su observancia ante sus respectivos tribunales". Tribunal de Justicia de la Comunidad Andina, TJCA, Sentencia, Proceso 2-N-86, República de Colombia contra Resolución 253 de la Junta, 10 de junio de 1987, 21 Gaceta Oficial, 15 de julio de 1987. Disponible en: intranet.comunidadandina.org/ Documentos/Procesos/2-N-86.doc (Junta del Acuerdo de Cartagena, Resolución 253, Aplicación del Artículo 80 del Acuerdo de Cartagena a solicitud del Gobierno de Colombia, 16 de abril de 1986. Derogada por la Resolución 285, 14 de abril de 1989 y la Resolución 287, de 15 de junio de 1989). También en el Proceso 78-IP-2009: "El ordenamiento jurídico comunitario andino, por regla general y en virtud de los principios de aplicación inmediata y efecto directo, entra a formar parte y a tener efecto automático en el sistema jurídico interno de los Países Miembros. En tal sentido, los operadores jurídicos internos deben aplicar el ordenamiento jurídico comunitario andino vigente (...) El Ordenamiento Jurídico Comunitario Andino tiene como principio fundamental el de "Preeminencia del Derecho Comunitario Andino". Dicho principio se encuentra soportado en otros tres principios: el de "Eficacia Directa del Ordenamiento Jurídico Andino", el de "Aplicación Inmediata del Ordenamiento Jurídico Andino", y el de "Autonomía del Ordenamiento Jurídico Andino". Tribunal de Justicia de la Comunidad Andina, TJCA, Sentencia, Proceso 78-IP-2009, 30 de septiembre de 2009. Disponible en: intranet.comunidadandina.org/Documentos/Procesos/2-N-86.doc 
Lo primero que se debe precisar es que el efecto directo de las normas comunitarias (tanto vertical como horizontal) solo ha tenido lugar en el contexto de la aplicación de la normativa de propiedad intelectual y del régimen de capitales extranjeros ${ }^{22}$. No hay antecedentes en materia de libre competencia y difícilmente existirán, mientras no se promueva una cultura de competencia que permita que las normas andinas se utilicen como fundamento de las reclamaciones que los particulares presentan ante los jueces nacionales. A la vista del sistema de aplicación establecido en la Decisión 608 de 2005 tal cultura solo puede tener origen nacional y a futuro consolidarse en el ámbito comunitario.

En segundo lugar, es preciso tener en cuenta que para que un sistema de private enforcement opere adecuadamente, es necesario que haya un sistema de public enforcement que funcione, que sea sólido y efectivo, en particular en lo que se refiere a la investigación y sanción de las conductas especialmente restrictivas (carteles). La buena gestión de las autoridades públicas se convierte en el soporte de las acciones de los particulares y, sensu contrario, la debilidad o ineficacia de las acciones administrativas constituye un obstáculo de las acciones privadas.

En tercer lugar, no puede perderse de vista que los factores que determinaron la implementación de un sistema de private enforcement en Europa no existen en el contexto andino. En Europa, la sobrecarga de trabajo de la Comisión y, en especial, la exclusividad de este órgano en la aplicación del sistema de exención fueron - junto al crecimiento y la expansión de la Unión Europea- los principales factores que motivaron la descentralización y la privatización de la aplicación de los artículos 101 y 102 del Tratado de Funcionamiento de la Unión Europea, TFUE ${ }^{23}$. En la Comunidad Andina no se cumple ninguno de los factores mencionados. El nivel de integración se complementa distinto, dado que la CAN es por ahora una unión aduanera; además, la CAN no tiene que hacer frente a un número

22 Galo Pico-Mantilla, La acción judicial de los particulares y la interpretación prejudicial en el Pacto Andino, en Temas Jurídicos de la Comunidad Andina, 199-212 (Secretaría General de la Comunidad Andina, Quito, diciembre de 2009). Disponible en: http://www.comunidadandina. org/BDA/docs/CAN-INT-0038.pdf

23 Unión Europea, Tratado de Funcionamiento de la Unión Europea, TFUE, Roma, 25 de marzo de 1957. Disponible en: http://eur-lex.europa.eu/legal-content/ES/ $\mathrm{TXT} /$ ?uri $=$ celex $\% 3 \mathrm{~A} 12012 \mathrm{E} \% 2 \mathrm{FTXT}$ 
creciente de integrantes ni mucho menos afrontar el problema de la centralización de la concesión de exenciones pues no hay una regulación detallada del tema ni un régimen de exenciones singulares. Así pues, no parece adecuado ofrecer el mismo tratamiento a situaciones completamente distintas.

Así las cosas, atendiendo el nivel actual de integración andina y la búsqueda de un mercado común ${ }^{24}$, consideramos necesario establecer un sistema adecuado de control sobre las conductas que pueden afectar la estructuración y el funcionamiento de este mercado; este sistema debería estar a cargo de las instancias comunitarias fortalecidas y de las autoridades nacionales. Lógicamente, la intervención de los jueces puede sobrevenir una vez se haya consolidado el modelo público, con el fin de complementar la actuación de los órganos comunitarios y administrativos del orden nacional ${ }^{25}$.

Por lo demás, es preciso comprender que las reformas al sistema de aplicación de las normas de libre competencia en Europa tuvieron lugar dentro de un proceso mucho mayor de cambio que fue la modernización de la legislación comunitaria de competencia. No tendría sentido que en el contexto andino se modifique únicamente el modelo de aplicación cuando hay otros aspectos y ámbitos en los que la reforma parece ser más necesaria y urgente, según lo hemos señalado y a los que cabría añadir la necesidad de un sistema de control de integraciones empresariales, la regulación de un sistema de exenciones singulares y la formulación de políticas de clemencia.

Conforme a las anteriores consideraciones, debemos admitir que el sistema de aplicación de las normas de libre competencia de carácter público ha sido y es conveniente tanto en el ámbito nacional como en el andino; que para evitar la dilución de las ventajas,

24 Bolivia, Colombia, Ecuador, Perú y Venezuela, Protocolo Modificatorio del Acuerdo de Cartagena, Protocolo de Quito, Quito, 12 de mayo de 1987, Artículo 2. Disponible en: https:// www.redjurista.com/documents/10060_87.aspx. Sobre los fines económicos de la integración: Luis Carlos Plata-López \& Donna Yepes-Ceballos, Naturaleza Jurídica de las normas comunitarias andinas, 31 Revista de Derecho, Universidad del Norte, 196-223, 204 (2009). Disponible en: http://ciruelo.uninorte.edu.co/pdf/derecho/31/8_NATURALEZA $\% 20 J U R I D I C A \% 20$ DE $\% 20 \mathrm{LAS} \% 20 \mathrm{~N} . \mathrm{pdf}$

25 “(...) It notes that 'the further maturation of Mexico's antitrust environment, especially in the courts, is necessary before private actions can become a significant feature of competition policy enforcement'. Judicial competence to try complex antitrust matters is a serious problem the world over, and may particularly be an issue in Latin America". Daniel Crane, Private Enforcement against International Cartels in Latin America: A US Perspective, en Competition Law and Policy in Latin America, 326-350, 341 (Eleanor M. Fox \& D. Daniel Sokol, eds., Hart Publishing, Oxford, 2009). 
de la experiencia y de los beneficios obtenidos debe reforzarse la actuación de las entidades públicas; y que solo en la medida en que se logre ese fortalecimiento será coherente y razonable admitir que los jueces nacionales intervengan en esa aplicación.

\section{AVANCES HACIA UN SISTEMA DE APLICACIÓN JUdicIal EN LOS PAÍses INTEGRANTES DE LA CAN}

Tal como lo anunciábamos en la introducción de este escrito, el panorama de la aplicación de las normas de libre competencia en la Comunidad Andina difiere por completo de la realidad que se viene gestando en cada uno de los Estados integrantes de esta comunidad.

En efecto, en todos los países integrantes de la CAN se vienen dando grandes pasos hacia la implementación del sistema de private enforcement con el fin de buscar una adecuada protección de las víctimas de las conductas anticompetitivas. Menores son las discusiones en torno a las acciones de nulidad al ser este un efecto regulado en el derecho civil, respecto del cual serían aplicables las vías procesales comunes y, en general, dado su menor impacto económico en la economía de las empresas.

Estos avances hacia un modelo inicialmente de corte anglosajón, actualmente adaptado a las necesidades y las tradiciones de derecho continental por medio de las normas europeas, seguramente producirán en los países andinos un cambio en la forma de ver, interpretar y aplicar las prohibiciones de las conductas restrictivas e igualmente un cambio en el papel de los particulares, los empresarios y los jueces respecto al acatamiento y aplicación de las normas de libre competencia.

\section{A. Cambios bajo el nuevo modelo de aplicación de las normas de libre competencia}

Uno de los principales cambios que exige la aceptación e implementación de un sistema de private enforcement es la modificación de la noción tradicional del ilícito anticoncurrencial o anticompetitivo. En efecto, en aquellos países que han acogido el modelo de aplicación de carácter público o administrativo, las infracciones a las 
normas de libre competencia se consideran exclusivamente ilícitos administrativos que alteran el orden público económico, vulneran los intereses generales y como tales deben ser objeto de sanciones de esta naturaleza. El nuevo modelo de aplicación exige considerar que las conductas anticompetitivas (conductas y abuso de la posición de dominio) son ilícitos duales, es decir, son conductas que no solo impactan el interés público o general que recae sobre el adecuado funcionamiento del mercado y los beneficios que este arroja, sino que además impactan los intereses y el patrimonio de los particulares directamente perjudicados por la conducta anticompetitiva.

En consonancia con el anterior, un segundo gran cambio consiste en admitir que el nuevo eje de aplicación de las normas de libre competencia está constituido por los efectos civiles o privados que derivan de la infracción, estos son: la nulidad absoluta de los acuerdos anticompetitivos y la responsabilidad civil de los infractores frente a las víctimas de los comportamientos restrictivos de la competencia. Este cambio implica la modificación del eje de desarrollo del derecho antitrust, pues conlleva tomar instituciones del derecho civil para hacerlas aplicables en el ámbito de la competencia y en consecuencia aproximar una normativa clásicamente considerada de naturaleza administrativa al derecho privado.

Respecto de los sujetos que intervienen en la aplicación de la normativa de libre competencia, el nuevo modelo implica un cambio en el rol que desempeñan los jueces y en las obligaciones a cargo de los particulares. Los jueces dejan de ser simples controladores de la actividad y de las decisiones de orden administrativo para asumir el deber de aplicar en forma directa (esto es, sin necesidad de que haya una decisión administrativa previa a las normas de libre competencia económica) las normas nacionales de libre competencia cuandoquiera que un particular haya invocado su infracción como fundamento de sus excepciones o pretensiones. El juez por lo tanto debe hacer las valoraciones propias del derecho de la competencia (la existencia de un mercado de referencia, de una situación de dominancia, de competidores actuales o potenciales, y de las situaciones de monopolio u oligopolio, etc.) para determinar si la infracción ha existido y por tanto definir los efectos civiles derivados de la misma. En cuanto a los particulares, es importante considerar que de ser simples denunciantes, en el modelo de aplicación privada se 
convierten en vigilantes del mercado y en agentes que garantizan el cumplimiento de esta normativa, en forma tal que aquellos casos que escapan a la autoridad nacional son objeto de control por parte de los jueces a solicitud de quienes se consideran víctimas de las conductas restrictivas de la competencia.

El modelo de aplicación privada implica dar respuesta a situaciones nuevas. Nos referimos a la necesidad de que haya mecanismos adecuados que permitan coordinar las acciones de los jueces (modelo privado) con las acciones y decisiones de las autoridades nacionales de competencia (modelo público) con el propósito de evitar actuaciones múltiples y decisiones contradictorias. Esto significa que el nuevo modelo no excluye la actuación ni las sanciones que pueden imponer las autoridades administrativas; por el contrario, las complementa en el sentido de satisfacer además del interés general los intereses de los particulares mediante el restablecimiento de las condiciones de competencia y el resarcimiento de los perjuicios padecidos ${ }^{26}$.

Finalmente, el modelo de aplicación privada exige atender cuidadosamente la adaptación de las normas civiles a las necesidades propias del mercado. Nos referimos a situaciones tales como la identificación de las víctimas, a la transmisión del daño en la cadena de comercialización y distribución de un producto en el mercado $\mathrm{y}$, por ende, al manejo de la denominada passing on defense, a la cuantificación de los daños frente a conductas de explotación y de

26 "The design puzzle is thus how to enable public enforcers to check excessive private enforcement without sacrificing the prospect of privately initiated class actions, which serve as check against deficient public enforcement. Professor Jill Fisch offers a thought-provoking design to address this conundrum, although it is not specifically tailored for the antitrust context. Fisch argues for establishing a qui tam-type process in which public enforcers would have an option to intervene and participate to some degree in litigating the private class action. The utility of this approach, however, depends on the extent of public enforcer involvement in the private class action, an issue that Fisch does not settle in her article. Resolving the ambiguity, however, is unlikely to solve the coordination problem. If the role of the public enforcer is merely to supply funding and other support, then the private check would be preserved, but there would be no public check against socially excessive private enforcement in cases that would otherwise attract too much private investment. Conversely, were public enforcers to take a more authoritative role, for example, invoking the prerogative of dictating limits on the theories of liability or amount of damages the class could assert, then the greater public check on excessive private enforcement would come at the expense of the private enforcer check on deficient public enforcement”. David Rosenberg \& James P. Sullivan, Coordinating Private Class Action and Public Agency Enforcement of Antitrust Law, 2 Journal of Competition Law and Economics, Oxford Press, 2, 159-187, 163 (2006). Disponible en: http://www.antitrustinstitute. org/files/rosenberg-sullivan\%20paper_121220081708.pdf 
exclusión y al resarcimiento efectivo de la víctima cuando esta ha sido partícipe de la ilicitud ${ }^{27}$.

\section{B. Los efectos jurídico-privados de las infracciones de competencia}

Entre los ordenamientos jurídicos de los países andinos y, en concreto, de sus normas nacionales de competencia se establecen las bases del modelo de enforcement privado, en primer lugar, porque admiten la intervención de los jueces en este ámbito y, en segundo lugar, porque reconocen los efectos civiles derivados de los ilícitos anticoncurrenciales.

En efecto, no obstante la preeminencia en los países andinos del modelo público, es preciso destacar que - en mayor o menor medida - en cada uno de ellos se acepta la intervención judicial, ya sea al asignarles la revisión de las decisiones administrativas adoptadas por las autoridades de competencia, o mediante el reconocimiento de competencias para la declaración de los efectos jurídico-privados (nulidad y responsabilidad civil) derivados de la infracción de las normas nacionales de competencia ${ }^{28}$.

27 Sobre la aplicación de las acciones de daños en el derecho de la competencia europeo y particularmente sobre las action classes, "Class actions do not exist in most continental European legal systems. However, most Member States legal systems do not preclude several parties, who have suffered damages as a result of the same course of action, from jointly bringing an action to seek redress. Moreover, in some Member States, consumer associations are specifically entitled to bring actions in the interest of consumers". GEORg Berrisch, Eve Jordan \& Rocío Salvador-Roldín, E.U. Competition and Private Actions for Damages, The Symposium on European Competition Law, 24 Northwestern Journal of International Law \& Business, 3, 585-600, 596 (Spring 2004). Disponible en: http://scholarlycommons.law.northwestern.edu/ cgi/viewcontent.cgi? article $=1582 \&$ context $=$ njilb

28 Sobre la problemática que ha traído la implementación de los efectos civiles del derecho de la competencia, como las acciones de daños y la de nulidad, Fernando Peña-LóPEZ expone: "Another important problem for the court is to deal with the consequences of contract nullity. There are two basic problems here: first to determine the scope of the declared nullity, and second to provide for the restitution of benefits between the parties. - Determining the scope of the nullity could be a complicated problem in some countries. In Spain, for instance, the general principle is that partial nullity can only be declared when it is specifically permitted by an Act or Statute (e.g. when one of the parties is a consumer). Otherwise, a partial nullity can only be decided if it is sure that both parties would have agreed with the contract without the void terms. If one of the parties wouldn't have agreed with the contract without the illegal terms, the whole contract must be declared void. - With this legal background, many times, the party interested in suppressing the unlawful terms will not sue, because he is more interested in keeping the contract alive, than in eliminate the illegal terms". Fernando PeÑa-LóPEZ, Issues and Problems Regarding E.U. Competition Law Private Enforcement: Damages and Nullity Actions, 13 The USV Annals of Economics and Public Administration, 1 (17), 230-235, 233 (2013). Disponible en: http://www.seap.usv.ro/annals/ojs/index.php/annals/article/viewFile/549/564 
Es preciso recordar también que la Decisión 608 de 2005 no contiene ninguna referencia en relación con los efectos civiles que derivan de las infracciones a las normas de libre competencia; según lo manifestamos ad supra, esta omisión no impide el reconocimiento y la aplicación de estos efectos en la medida en que se fundamenta en las normas generales de derecho privado de cada uno de los Estados miembros.

Contrario a esta situación, las normas nacionales de competencia de los países andinos sí prevén los efectos civiles derivados de las infracciones a las normas de libre competencia y la competencia (directa o indirecta) de los jueces para proceder a su declaración.

Un punto en el que aún no hay unanimidad es si los jueces nacionales pueden pronunciarse en forma directa sobre las infracciones civiles o si en cambio solo pueden hacerlo cuando hay una declaración previa sobre la ilicitud de la conducta por parte de la autoridad de competencia. Desde luego, este tema será crucial para definir el grado de independencia con que actúan los jueces y la inmediatez con que deben resolver las demandas sobre la indemnización de los daños y perjuicios.

Respecto a la aplicación directa y por ende no condicionada a la decisión administrativa previa sobre la ilicitud de la conducta, es importante recordar la experiencia de Europa. Precisamente, el Reglamento CE 1/2003 implicó un avance significativo en torno al sistema de private enforcement en la medida en que reconoció de forma expresa en su artículo 6 la facultad de los jueces nacionales para aplicar los artículos 101 y 102 del TFUE que prohíben los acuerdos restrictivos de la competencia y el abuso de la posición de dominio, sin que tuviese que haber una decisión previa en este sentido por parte de la Comisión Europea o de las autoridades nacionales de competencia. La intervención directa del juez trajo un gran cambio en la medida en que garantizaba su plena independencia y una aplicación más rápida de las normas y por ende un resarcimiento más efectivo de las víctimas ${ }^{29}$.

Al contrario de la experiencia comunitaria, algunos países como España — aún con posterioridad al Reglamento (CE) 1/2003- establecían en sus normas nacionales que la posibilidad de reclamar

29 Michael D. Hausfeld, The Importance of Private Competition Enforcement in Europe, 8 Competition Law International, 2, 65-72 (August 2012). 
daños y perjuicios solo era posible cuando la autoridad de competencia hubiera declarado previamente la ilicitud de la conducta (artículo 13.2 de Ley 16 de 1989) ${ }^{30}$. Por supuesto, este sistema implicaba muchos riesgos y largos períodos de espera para las víctimas que tenían que tramitar primero un procedimiento administrativo y solo una vez concluido este y habiéndose obtenido una decisión en firme, tenían la posibilidad de acudir ante los jueces nacionales. Estos inconvenientes - junto con la transformación operada en el ámbito europeo-determinaron que en la reforma a la Ley 16 de 1989, el legislador español incluyera - como ya lo había hecho el legislador comunitario - una norma que expresamente autorizaba a los jueces nacionales a aplicar directamente las normas tanto nacionales como comunitarias de libre competencia y a decidir de forma inmediata y directa sobre las reclamaciones relativas a los efectos jurídicos privados ${ }^{31}$.

Hechas estas anotaciones, a continuación se realiza un estudio comparativo sobre la regulación de los efectos civiles o jurídicoprivados en la legislación nacional de competencia de los distintos países andinos ${ }^{32}$.

30 España, Ley 16 de 1989, de 17 de julio, de Defensa de la competencia, 170 Boletín Oficial del Estado, BOE, 18 de julio de 1989. Disponible en: https://www.boe.es/buscar/doc.php?id=BOEA-1989-16989

31 Sin embargo, la confluencia entre las acciones de daños y el modelo público de aplicación de derecho de la competencia ha traído algunos inconvenientes en la aplicación y revelación de cierta información restringida, y protegida por el modelo público relacionado con los programas de clemencia o delación. Se destaca el caso Pfleiderer, sobre el cual se puede encontrar información en ROGER GAMBLE: "At the heart of the current tension is the question of whether the information provided by an immunity applicant should, as against a third party claiming damages from cartel members, including the leniency applicant, remain confidential. In most jurisdictions, immunity policy documents or guidelines, whilst providing no guarantees that information provided by immunity applicants will be treated as confidential, do, to different degrees, endorse confidentiality. How- ever, in other non-policy documents or speeches, regulators are more forthcoming about the need for confidentiality". Roger GAMBLE, The Cartel Penumbra: Where Public and Private Enforcement Policies Intersect, 42 Common Law World Review, 1, 23-47 (2013). Tribunal de Justicia de las Comunidades Europeas, Gran Sala, Sentencia, Asunto C-360/09, Caso Pfleiderer AG contra Bundeskartellamt, 14 de junio de 2011, Disponible en: http://curia.europa.eu/juris/liste.jsf?language=es\&num=C-360/09

32 Sobre la experiencia en países desarrollados en la implementación de modelos de private enforcement en países en desarrollo, James Kirkbride, Steve Letza \& Dujuan Yuan, The Challenges of Private Antitrust Enforcement in Transition Economies: The Case of Brazil, 52 International Journal of Law \& Management, 6, 451-463 (2010). 


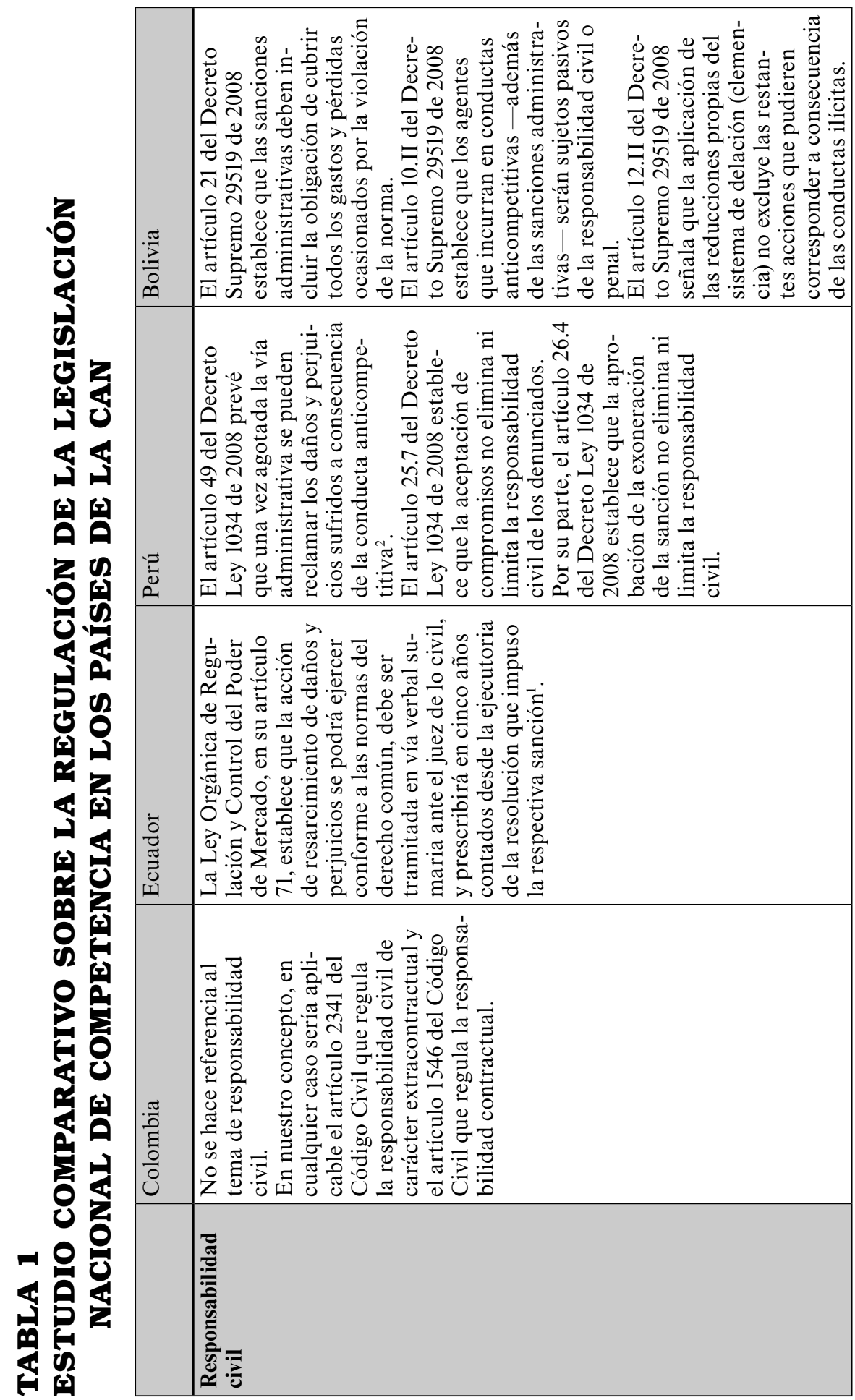




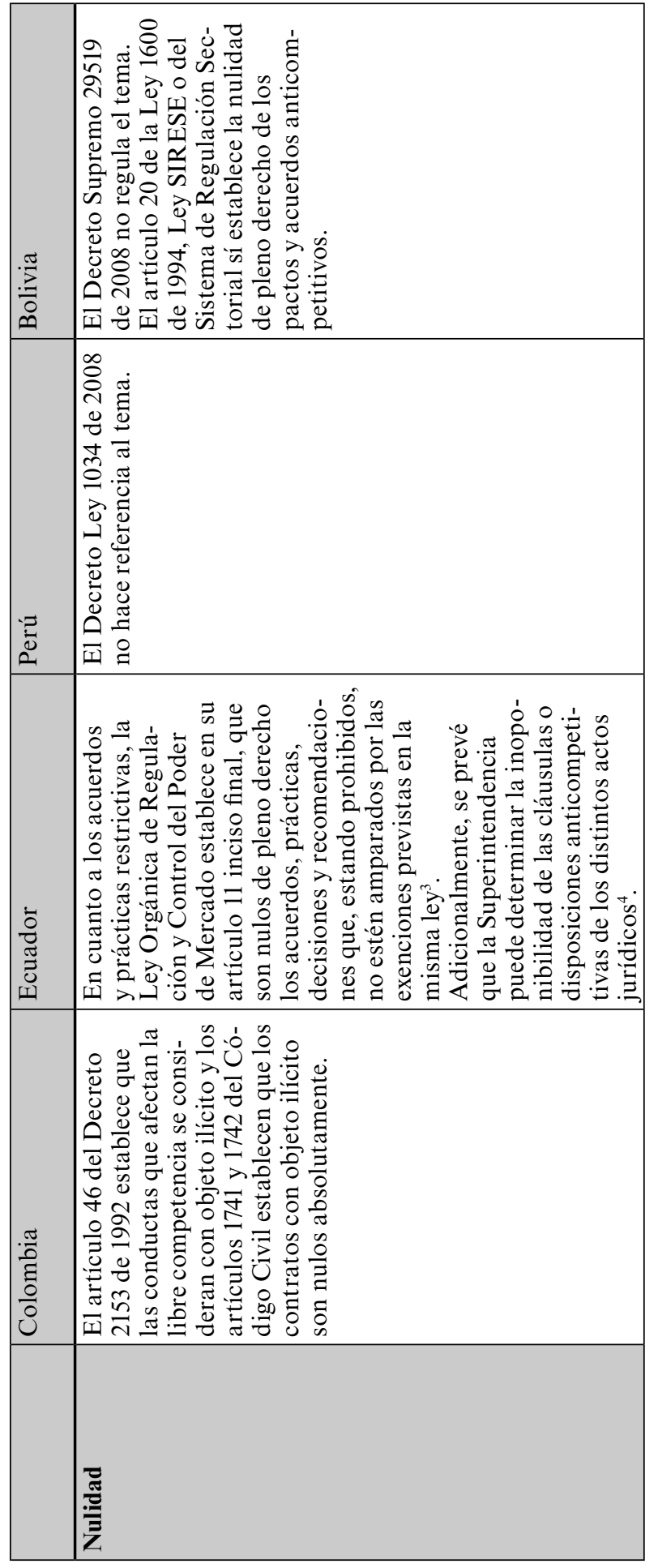

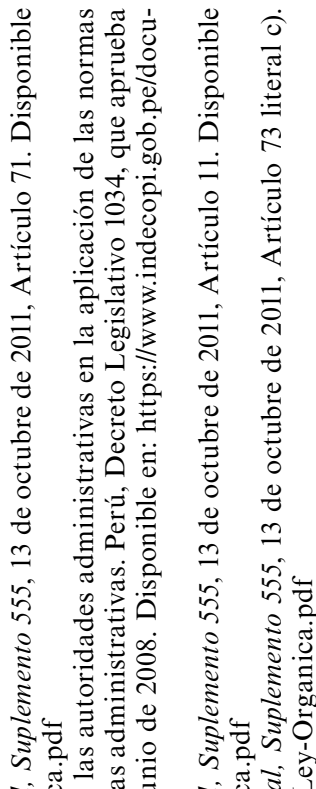

के⿺辶寸

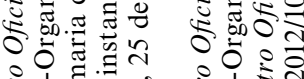

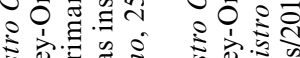

क्षे

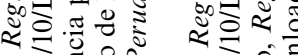

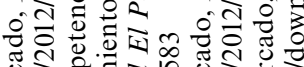

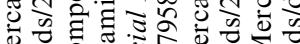

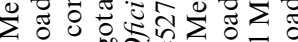

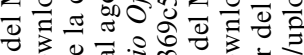

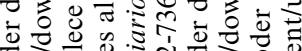

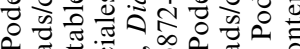

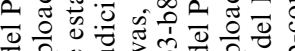

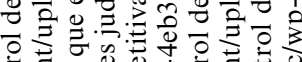

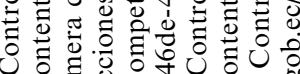

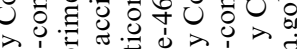

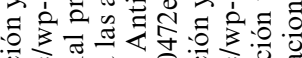

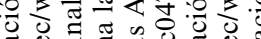
ㅂ. 500.000000 थ

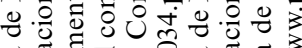

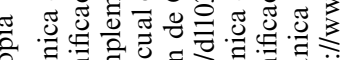

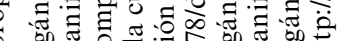
娄要

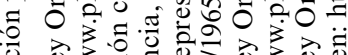

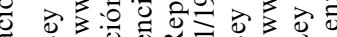

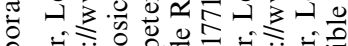

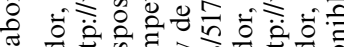

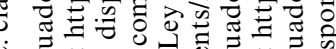

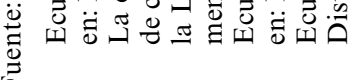


El cuadro comparativo arroja las siguientes conclusiones:

La sanción de la nulidad absoluta de los acuerdos restrictivos de la competencia está expresamente regulada en la normativa de Colombia y Ecuador. La legislación sectorial de Bolivia también prevé esta sanción civili33.

A nuestro juicio, el vacío que sobre el tema de la nulidad existe en la legislación peruana no impide que en ese ordenamiento pueda tener lugar la aplicación de esta sanción civil, pues para ello bastaría con reconocer que las disposiciones de libre competencia son normas de orden público y, posteriormente, acudir a las disposiciones civiles que sancionan con nulidad todo acuerdo, acto o pacto contrario a este tipo de normas ${ }^{34}$.

Las normas consagran la nulidad del acuerdo anticompetitivo por lo que en este punto habrá que aplicar las reglas de conservación del negocio jurídico, de manera tal que solo se prive de efectos el pacto anticompetitivo contenido en la cláusula negocial y se conserve la validez de los restantes acuerdos. Esta regla tendrá lugar salvo en el caso de que la cláusula afectada por la nulidad resulte esencial al negocio o lo sea para una de las partes, en forma tal que esta pierda todo interés en continuar con el negocio celebrado, evento en el cual la nulidad absoluta afectará la totalidad del negocio jurídico ${ }^{35}$.

Nada dicen las normas nacionales de competencia sobre la afectación por nulidad de los negocios jurídicos derivados o coliga-

33 En Bolivia, más que discutir la aplicación de la sanción, se ha debatido si las superintendencias del sistema SIRESE, en su calidad de entidades administrativas, pueden aplicar esta sanción civil. También se ha discutido si, siendo la nulidad de pleno derecho, sería necesaria la intervención de una autoridad. Bolivia, Decreto Supremo 24505, Reglamento a la Ley del Sistema de Regulación Sectorial, SIRESE, 21 de febrero de 1997. Disponible en: http://www. lexivox.org/norms/BO-DS-24505.xhtml

34 Concretamente, se podrían aplicar el artículo 5 del Código Civil del Perú y artículo 9 del Código Civil del Ecuador. Perú, Decreto Legislativo 295, Código Civil, 24 de julio de 1984. Disponible en: http://www.oas.org/juridico/pdfs/mesicic4_per_cod_civil.pdf. Ecuador, Código Civil. Disponible en: http://www.wipo.int/edocs/lexdocs/laws/es/ec/ec055es.pdf

35 "El sentido de la norma sobre la nulidad parcial objetiva se explica, más bien, en consideración de su razón, que es la de conservar el contrato, salvo que la modificación del contenido sea tal que no justifique, objetivamente, que se mantenga. Lo que se exige es, entonces una valoración de compatibilidad de la modificación del contrato con la causa concreta del mismo, pues se debe verificar, en definitiva, si la modificación tiene o no importancia determinante, teniendo en cuenta el interés de las partes. Este criterio coincide así con aquel previsto para la nulidad parcial en sentido objetivo". C. Massimo Bianca, Derecho Civil, 3 El contrato, 660 (Fernando Hinestrosa \& Édgar Cortés, trads., Universidad Externado de Colombia, Bogotá, 2007). 
$\operatorname{dos}^{36}$ con aquel que contiene la restricción anticompetitiva; en este sentido habrá de nuevo que acudir a la teoría general del negocio jurídico para definir si eventualmente habría lugar a aplicar una nulidad en cascada ${ }^{37}$.

En cuanto a la responsabilidad civil derivada de las infracciones a las normas de libre competencia, resulta llamativo que expresamente las legislaciones de Bolivia, de Perú y de Ecuador regulen este efecto jurídico-privado y, particularmente que lo hagan, escindiendo su existencia del ámbito de las competencias y las sanciones de naturaleza administrativa. A nuestro juicio, estas disposiciones son una prueba más del impacto que han tenido las normas y avances europeos sobre las reformas implementadas en las legislaciones de competencia de los países latinoamericanos ${ }^{38}$.

En el ordenamiento colombiano la falta de una mención específica a la responsabilidad civil derivada de los ilícitos anticoncurrenciales no ha sido un impedimento para que la Superintendencia de Industria y Comercio (en adelante, SIC) admita la procedencia de estas acciones con fundamento en las normas civiles que regulan la responsabilidad civil general de carácter extracontractual ${ }^{39}$.

36 "A este propósito es necesario observar que la coligación funcional comporta la unidad del interés globalmente perseguido, pero no descarta que tal interés se realice por medio de contratos diferentes, y que son parciales o instrumentales respecto de aquel interés unitario que se persigue con el conjunto de contratos. En los contratos coligados se debe identificar, por lo tanto, la causa parcial de los contratos en particular y la causa compleja de la operación". C. Massimo Bianca, Derecho Civil, 3 El contrato, 504 (Fernando Hinestrosa \& Édgar Cortés, trads., Universidad Externado de Colombia, Bogotá, 2007).

37 "A los contratos coligados se aplican, por lo tanto, las reglas de la nulidad parcial, de donde la invalidez de un contrato puede comportar la invalidez de los otros que a él están ligados (...)". C. Massimo Bianca, Derecho Civil, 3 El contrato, 660 (Fernando Hinestrosa \& Édgar CorTÉs, trads., Universidad Externado de Colombia, Bogotá, 2007).

38 Sobre el particular, en Colombia, el Proyecto de Ley 38 de 2015, Senado, contempla en su artículo 12 la modificación de las facultades en sede jurisdiccional conferidas a la Superintendencia de Industria, otorgándole competencia en materia de acciones de daños derivadas de la vulneración al régimen de prácticas restrictivas de la competencia. A renglón seguido: "Artículo 24. Ejercicio de funciones jurisdiccionales por autoridades administrativas. Las autoridades administrativas a que se refiere este artículo ejercerán funciones jurisdiccionales conforme a las siguientes reglas: 1. La Superintendencia de Industria y Comercio en los procesos que versen sobre: (...) c) La indemnización de perjuicios en acciones individuales o de grupo derivados de la violación de normas sobre prácticas restrictivas de la competencia”. Proyecto de Ley 38 de 2015, Senado, por medio por la cual se introducen modificaciones al régimen de protección de la competencia, a las funciones de la Superintendencia de Industria y Comercio, y se dictan otras disposiciones, 587 Gaceta del Congreso, 6 de agosto de 2015. Disponible en: http://www. imprenta.gov.co/gacetap/gaceta.mostrar_documento?p_tipo $=05 \&$ p_numero $=38 \&$ p_consec $=$ 42414, http://www.imprenta.gov.co/gacetap/gaceta.indice?v_num=567\&v_anog=2015

39 Apartado II, Avances hacia un sistema de aplicación judicial en los países integrantes de la CAN, ad supra. 
La normativa peruana se refiere de manera expresa a la necesidad de acudir y de agotar el procedimiento administrativo sancionador de forma previa a la reclamación judicial de los daños, lo que indica que la intervención judicial siempre será posterior y, en consecuencia, que las acciones de daños serán acciones follow on o acciones consecutivas $^{40}$. Por su parte, en Ecuador, la Ley Orgánica de Regulación y Control del Poder de Mercado establece en su artículo 71 que el término de prescripción de la acción de resarcimiento de daños y perjuicios se cuenta a partir de la ejecutoria de la resolución que impuso la respectiva sanción. Sobre esta norma resulta posible afirmar que también en el ordenamiento de Ecuador es necesario adelantar el proceso administrativo y que solo una vez agotado este trámite y habiéndose obtenido una decisión de sanción es posible adelantar ante los jueces nacionales la reclamación de daños y perjuicios.

En Colombia, la doctrina ha aceptado que los jueces pueden aplicar de manera directa las disposiciones de competencia tanto para pronunciarse sobre la nulidad como para declarar la responsabilidad civil de los infractores. Es decir, se ha considerado que hay una competencia judicial plena y directa y que la decisión administrativa no constituye un prerrequisito para la intervención de los jueces ni tampoco condiciona su alcance. Sin embargo, el tema aún está abierto a discusión comoquiera que en el terreno práctico no han tenido lugar reclamaciones de esta naturaleza.

40 Destaca en particular la regulación de la responsabilidad por ilícitos anticoncurrenciales incluida en el artículo 49 del Decreto Ley 1034 de 2008 (Perú), no solo por su novedad y la importancia que puede tener como modelo en la región, sino además porque condiciona las acciones civiles al agotamiento previo de la vía administrativa, lo que claramente indica de la prevalencia y confianza en el modelo público. Sobre el tema, puede verse Jorge SANTiSTEVAN DE NORIEGA: "En este marco si el género ("responsabilidad extracontractual") se encuentra regulado bajo la figura abierta del artículo 1969 del Código Civil, la especie ("responsabilidad extracontractual derivada de la contravención a las normas de libre competencia") se encuentra regida por las conductas contrarias a la libre competencia tipificadas en su momento en el Decreto Ley 701 (y en la actualidad por el Decreto Legislativo 1034, siendo requisito para demandar pretensión indemnizatoria por daños y perjuicios el agotar la vía administrativa, a fin de que sea la Administración quien determine la antijuridicidad establecida por el artículo 25 de la norma citada en primer lugar y el artículo 16 de la Ley 25868 (hoy por el artículo 49 de la última de las normas mencionadas), a lo que habrá que añadir lo dispuesto por el mencionado artículo 1969 en lo relativo a los demás elementos constitutivos de la responsabilidad civil”. Jorge SANTISTEVAN DE NorIEGA, Responsabilidad extracontractual derivada de conductas anticompetitivas: tipicidad, antijuricidad y calificación previa por parte de la administración, 6 Revista de la Competencia y la Propiedad Intelectual, 89-148, 103 (2008). Disponible en: http:// servicio.indecopi.gob.pe/revistaCompetencia/castellano/articulos/otono2008/Santistevan.pdf 
En Bolivia, el tema no ha sido aún objeto de discusión; pese a ello, la preferencia por la intervención y por la acción de las entidades administrativas hace prever que la acción judicial será siempre posterior a la decisión administrativa sancionadora.

Creemos que al igual que ha sucedido en Europa, el carácter prevalente de la acción de las autoridades nacionales de competencia, los poderes con que estas entidades cuentan para investigar e identificar en un sector determinado las conductas restrictivas y la experiencia de la que disponen en este campo harán que la acción de los particulares sea siempre posterior a la decisión administrativa de infracción. En la mayoría de los casos, sobre todo frente a conductas especialmente restrictivas, el particular no está en capacidad (económica y de medios en general) de probar una conducta ilícita, por lo cual preferirá que sea la autoridad de competencia la que adelante esta fase y acudir al juez una vez tenga una decisión administrativa firme que constituye una prueba contundente y favorable a sus pretensiones resarcitorias.

Hechas estas observaciones, se deja en evidencia que el tema de los efectos jurídico-privados $\mathrm{y}$, fundamentalmente, de las acciones de daños por ilícitos antitrust, no es indiferente para los legisladores nacionales ${ }^{41}$. Sin embargo, la falta absoluta de antecedentes prácticos demuestra que los operadores económicos (empresarios y consumidores) no están familiarizados con el tema y/o que aún prefieren la acción de las autoridades nacionales y la imposición de multas. Esta situación reafirma una vez más la necesidad de fortalecer el enforcement público para crear una cultura de competencia que al final pueda revertir y consolidar las acciones de carácter privado.

Atendiendo las consideraciones hechas en los apartados anteriores podemos concluir que:

m. Es necesario fortalecer la aplicación pública en el ámbito andino.

n. Resulta vital profundizar la integración económica, lograr una adecuada armonización entre los ordenamientos nacionales y fortalecer la acción de las autoridades nacionales en cuanto a la

41 Por lo menos en lo que atañe a la CAN, la afirmación de DANIEL CRANE en relación con la falta de acciones para la defensa de los derechos e intereses privados no es cierta. DANIEL Crane, Private Enforcement against International Cartels in Latin America: A US Perspective, en Competition Law and Policy in Latin America, 326-350, 326 (EleAnor M. Fox \& D. DanieL SoKol, eds., Hart Publishing, Oxford, 2009). 
aplicación de las normas de la Decisión 608 de 2005 y las normas de cada uno de los países integrantes de la CAN.

o. El avance hacia el modelo de aplicación judicial debería $-\mathrm{y}$ seguramente así será - empezar en el ámbito nacional. Los jueces de cada Estado deben ver fortalecidos sus poderes y su rol en la aplicación de las normas nacionales para a posteriori aplicar adecuadamente las normas andinas.

p. En coherencia con esta perspectiva, los ordenamientos nacionales andinos disponen ya de bases importantes para promover el desarrollo de un sistema de private enforcement, por lo que a futuro y sobre estos cimientos podría construirse un modelo comunitario. 


\section{CONCLUSIONES}

1. El sistema de aplicación judicial o privada implica un cambio en la forma de analizar y concebir las conductas restrictivas de la competencia que como tales, pasan a considerarse ilícitos duales en la medida en que impactan en el funcionamiento del mercado y en los intereses de los particulares que resultan afectados por la realización de los acuerdos o actos anticompetitivos o bien de conductas constitutivas de abuso de la posición de dominio.

2. El debate actual no se refiere a la exclusividad o preeminencia del modelo privado sobre el modelo público o administrativo de aplicación de las normas de competencia, sino a la necesidad de lograr un funcionamiento coordinado y coherente de los dos modelos para poder obtener las ventajas que derivan de cada uno de ellos.

3. El análisis sobre la posible estructuración de un modelo privado en la Comunidad Andina no puede hacerse a partir de las experiencias foráneas. En el estado actual de la integración y el desarrollo del derecho de la competencia en el ámbito comunitario, es necesario analizar las ventajas y los beneficios que hasta el momento ha arrojado el funcionamiento del modelo público y adoptar las medidas adecuadas para su fortalecimiento y consolidación previa la estructuración y el desarrollo de un sistema en el que los jueces y las acciones de los particulares constituyen los principales supuestos de la aplicación de las normas de libre competencia.

4. En cuanto a los Estados miembros de la CAN, también consideramos necesario valorar las ventajas del modelo público y adoptar las medidas tendientes a su fortalecimiento. No obstante, dado que las normas nacionales ya han sentado las bases de un sistema de aplicación privada, estimamos que hay los presupuestos para dar cabida a este nuevo modelo, disponiendo por supuesto de los elementos necesarios por medio de los cuales se garantice que las autoridades administrativas y judiciales podrán coexistir y funcionar de manera coherente.

5. Las normas de libre competencia y las normas generales de derecho privado constituyen las bases sobre las cuales se puede afirmar que las víctimas de las conductas anticompetitivas tie- 
nen abierta la vía de la reclamación de los daños derivados de las conductas anticompetitivas y también la acción de nulidad respecto de los acuerdos anticompetitivos.

6. Las acciones de daños derivadas de la infracción de las normas de competencia tienen fundamento en las normas generales que regulan la responsabilidad extracontractual y contractual. Los elementos estructurales de esa responsabilidad son igualmente los que corresponden al régimen general: conducta ilícita, daño, relación causal, factor de imputación e indemnización de perjuicios.

7. Entre los elementos estructurales de la responsabilidad, tanto la noción de daño como los sistemas de indemnización de perjuicios son puntos de especial relevancia y conflictividad. Sobre estos elementos y, en especial, sobre los métodos para cuantificar los daños frente a conductas de explotación y de exclusión, la Comisión Europea y la doctrina en este ámbito han avanzado considerablemente. Estos avances pueden ser útiles como modelo para introducir el debate del tema en la CAN y en Colombia. 


\section{BIBLIOGRAFÍA}

\section{Libros}

Bianca, C. Massimo, Derecho Civil, 3 El contrato (Fernando Hinestrosa \& Édgar CorTÉs, trads., Universidad Externado de Colombia, Bogotá, 2007).

Pico-Mantilla, Galo, La acción judicial de los particulares y la interpretación prejudicial en el Pacto Andino, en Temas Jurídicos de la Comunidad Andina, 199-212 (Secretaría General de la Comunidad Andina, Quito, diciembre de 2009). Disponible en: http://www.comunidadandina.org/BDA/docs/CAN-INT-0038.pdf

\section{Colaboración en obras colectivas}

Crane, Daniel, Private Enforcement against International Cartels in Latin America: A US Perspective, en Competition Law and Policy in Latin America, 326-350 (Eleanor M. Fox \& D. Daniel Sokol, eds., Hart Publishing, Oxford, 2009).

Rosales, Osvaldo, Integración regional: propuestas de renovación, en Paradojas de la Integración en América Latina y el Caribe, 33-66 (Josette Altmann, Francisco Rojas-AravenA, eds., Facultad Latinoamericana de Ciencias Sociales, FLACSO, Organización de Naciones Unidas, ONU, Comisión Económica para América Latina y el Caribe, CEPAL, Fundación Carolina de España, Siglo XXI Editores, 2008).

\section{Revistas}

Berrisch, Georg; Jordan, Eve \& Salvador-Roldán, Rocío, E.U. Competition and Private Actions for Damages, The Symposium on European Competition Law, 24 Northwestern Journal of International Law \& Business, 3, 585-600 (Spring 2004). Disponible en: http://scholarlycommons.law.northwestern.edu/cgi/viewcontent. cgi? article $=1582 \&$ context $=$ njilb

Gamble, Roger, The Cartel Penumbra: Where Public and Private Enforcement Policies Intersect, 42 Common Law World Review, 1, 23-47 (2013).

Hausfeld, Michael D., The Importance of Private Competition Enforcement in Europe, 8 Competition Law International, 2, 65-72 (August 2012).

Kirk bride, James; Letza, Steve \& Yuan, Dujuan, The Challenges of Private Antitrust Enforcement in Transition Economies: The Case of Brazil, 52 International Journal of Law \& Management, 6, 451-463 (2010).

Marcos, Francisco, ¿Una política de competencia para la República de Ecuador?, 21 Boletín Latinoamericano de Competencia, 2, 29-39 (febrero de 2006). Disponible en: http://ec.europa.eu/competition/publications/blc/boletin_21_2.pdf

Otero, Lorena, El Derecho de la competencia en Bolivia, 2 Revista Centro de Estudios Derecho de la Competencia, 2, 15-31 (2006). Disponible en: https://centrocedec. files.wordpress.com/2010/06/1-el-dercho-de-1.pdf 
Peña-López, Fernando, Issues and Problems Regarding E.U. Competition Law Private Enforcement: Damages and Nullity Actions, 13 The USV Annals of Economics and Public Administration, 1 (17), 230-235 (2013). Disponible en: http://www.seap. usv.ro/annals/ojs/index.php/annals/article/viewFile/549/564

Pérez-Fernández, Patricia, La problemática relación entre los programas de clemencia y las acciones privadas de resarcimiento de los daños derivados de ilícitos antitrust, 1 InDret, Revista para el Análisis del Derecho, 1-23 (2013). Disponible en: http:/l www.raco.cat/index.php/InDret/article/download/262214/349397

Plata-López, Luis Carlos \& Yepes-Ceballos, Donna, Naturaleza Jurídica de las normas comunitarias andinas, 31 Revista de Derecho, Universidad del Norte, 196-223 (2009). Disponible en: http://ciruelo.uninorte.edu.co/pdf/derecho/31/8_ NATURALEZA \%20JURIDICA\%20DE\%20LAS\%20N.pdf

Rosenberg, David \& Sullivan, James P., Coordinating Private Class Action and Public Agency Enforcement of Antitrust Law, 2 Journal of Competition Law and Economics, Oxford Press, 2, 159-187 (2006). Disponible en: http://www. antitrustinstitute.org/files/rosenberg-sullivan\%20paper_121220081708.pdf

SAntistevan de Noriega, JoRge, Responsabilidad extracontractual derivada de conductas anticompetitivas: tipicidad, antijuricidad y calificación previa por parte de la administración, 6 Revista de la Competencia y la Propiedad Intelectual, 89-148 (2008). Disponible en: http://servicio.indecopi.gob.pe/revistaCompetencia/ castellano/articulos/otono2008/Santistevan.pdf

Vela, Bernardo, La encrucijada del proceso andino de integración, 12 Oasis, 425-432 (2007). Disponible en: http://revistas.uexternado.edu.co/index.php/oasis/article/ view/2432/2070

\section{Working paper}

Gutiér rez-Rodríguez, JuAn David, La legislación de competencia en América Latina y el Caribe: historia, vigencia, aplicación y reformas (Centro de Estudios de Derecho de la Competencia, Working paper 07-05, 2007). Disponible en: http://papers. ssrn.com/sol3/papers.cfm?abstract_id $=1023811$

\section{Tratados internacionales}

Bolivia, Colombia, Ecuador, Perú y Venezuela, Protocolo Modificatorio del Acuerdo de Cartagena, Protocolo de Quito, Quito, 12 de mayo de 1987. Disponible en: https://www.redjurista.com/documents/10060_87.aspx

Colombia \& Estados Unidos, Acuerdo de Promoción Comercial entre la República de Colombia y Estados Unidos de América, TLC, Washington D.C., 22 de noviembre de 2006, vigente desde el 15 de mayo de 2012. Disponible en: http:// www.tlc.gov.co/publicaciones.php?id=14853

Perú \& Estados Unidos, Acuerdo de Promoción Comercial Perú-Estados Unidos, TLC, Washington D.C., 12 de abril de 2006, vigente desde el 1 de febrero de 2009. Disponible en: http://www.acuerdoscomerciales.gob.pe/index.php?option=com 
content $\&$ view $=$ category $\&$ layout $=$ blog $\& \mathrm{id}=55 \&$ Itemid $=78$

Unión Europea, Tratado de Funcionamiento de la Unión Europea, TFUE, Roma, 25 de marzo de 1957. Disponible en: http://eur-lex.europa.eu/legal-content/ES/ $\mathrm{TXT} /$ ?uri $=$ celex $\% 3 \mathrm{~A} 12012 \mathrm{E} \% 2 \mathrm{FTXT}$

\section{Normatividad internacional}

Bolivia, Decreto Supremo 24505, Reglamento a la Ley del Sistema de Regulación Sectorial, SIRESE, 21 de febrero de 1997. Disponible en: http://www.lexivox. org/norms/BO-DS-24505.xhtml

Bolivia, Decreto Supremo 29519, que regula la competencia y la defensa del consumidor frente a conductas lesivas, 16 de abril de 2008. Disponible en: http://www. autoridadempresas.gob.bo/marco-legal/decretos-supremos

Comisión de la Comunidad Andina, CAN, Decisión 608/2005, Normas para la protección y promoción de la libre competencia en la Comunidad Andina, Lima, Perú, 28 de marzo de 2005. Disponible en: http://intranet.comunidadandina.org/ Documentos/decisiones/DEC608.doc

Consejo de la Unión Europea, Reglamento (CE) 1/2003 del Consejo, de 16 de diciembre de 2002, relativo a la aplicación de las normas sobre competencia previstas en los artículos 81 y 82 del Tratado, L1 Diario Oficial de las Comunidades Europeas, 4 de enero de 2003. Disponible en: http://eur-lex.europa.eu/LexUriServ/LexUriServ. do?uri=OJ:L:2003:001:0001:0025:ES:PDF

Ecuador, Código Civil. Disponible en: http://www.wipo.int/edocs/lexdocs/laws/es/ec/ ec055es.pdf

Ecuador, Ley Orgánica de Regulación y Control del Poder del Mercado, Registro Oficial, Suplemento 555, 13 de octubre de 2011. Disponible en: http://www.planificacion. gob.ec/wp-content/uploads/downloads/2012/10/Ley-Organica.pdf

España, Ley 16 de 1989, de 17 de julio, de Defensa de la competencia, 170 Boletín Oficial del Estado, BOE, 18 de julio de 1989. Disponible en: https://www.boe.es/buscar/ doc.php?id=BOE-A-1989-16989

Perú, Decreto Legislativo 295, Código Civil, 24 de julio de 1984. Disponible en: http:// www.oas.org/juridico/pdfs/mesicic4_per_cod_civil.pdf

Perú, Decreto Legislativo 1034, que aprueba la Ley de Represión de Conductas Anticompetitivas, Diario Oficial El Peruano, 25 de junio de 2008. Disponible en: https://www.indecopi.gob.pe/documents/51771/196578/d11034.pdf/66c0472e46de-4eb3-b872-7369c5279583

\section{Normatividad colombiana}

Colombia, Decreto 2153 de 1992, por el cual se reestructura la Superintendencia de Industria y Comercio y se dictan otras disposiciones, 40.704 Diario Oficial, $31 \mathrm{de}$ diciembre de 1992. Disponible en: http://www.secretariasenado.gov.co/senado/ basedoc/decreto_2153_1992.html 
Colombia, Ley 57 de 1887, por la cual se expide Código Civil, 15 de abril de 1887. Disponible en: http://www.secretariasenado.gov.co/senado/basedoc/codigo_civil. html

Colombia, Ley 155 de 1959, por la cual se dictan algunas disposiciones sobre prácticas comerciales restrictivas, 30.138 Diario Oficial, 22 de enero de 1960. Disponible en: http://www.alcaldiabogota.gov.co/sisjur/normas/Norma1.jsp?i=38169

Colombia, Ley 1340 de 2009, por medio de la cual se dictan normas en materia de protección de la competencia, 47.420 Diario Oficial, 24 de julio de 2009. Disponible en: http://www.secretariasenado.gov.co/senado/basedoc/ley_1340_2009.html

\section{Jurisprudencia}

Junta del Acuerdo de Cartagena, Resolución 253, Aplicación del Artículo 80 del Acuerdo de Cartagena a solicitud del Gobierno de Colombia, 16 de abril de 1986. Derogada por la Resolución 285, 14 de abril de 1989 y la Resolución 287, de 15 de junio de 1989.

Tribunal de Justicia de la Comunidad Andina, TJCA, Sentencia, Proceso 2-N-86, República de Colombia contra Resolución 253 de la Junta, 10 de junio de 1987, 21 Gaceta Oficial, 15 de julio de 1987. Disponible en: intranet.comunidadandina. org/Documentos/Procesos/2-N-86.doc

Tribunal de Justicia de la Comunidad Andina, TJCA, Sentencia, Proceso 78-IP-2009, 30 de septiembre de 2009. Disponible en: intranet.comunidadandina.org/ Documentos/Procesos/2-N-86.doc

Tribunal de Justicia de las Comunidades Europeas, Gran Sala, Sentencia, Asunto C-360/09, Caso Pfleiderer AG contra Bundeskartellamt, 14 de junio de 2011, Disponible en: http://curia.europa.eu/juris/liste.jsf?language $=$ es\&num=C-360/09

\section{Proyectos de Ley colombianos}

Proyecto de Ley 38 de 2015, Senado, por medio por la cual se introducen modificaciones al régimen de protección de la competencia, a las funciones de la Superintendencia de Industria y Comercio, y se dictan otras disposiciones, 587 Gaceta del Congreso, 6 de agosto de 2015. Disponible en: http://www.imprenta.gov.co/gacetap/gaceta. mostrar_documento?p_tipo $=05 \&$ p_numero $=38 \&$ p_consec $=42414$, http: $/ / \mathrm{www}$. imprenta.gov.co/gacetap/gaceta.indice?v_num $=567 \&$ v_anog $=2015$

\section{Direcciones web}

http://www.oecd.org/document/36/0,3343,en_40382599_40393122_40424036_1_1_1_1,00. html 
